\title{
Atherothrombosis and Plaque Heterology: Different Location or a Unique Disease?
}

\author{
M. Slevin ${ }^{a}$ Q. Wang ${ }^{a}$ M. Angels Font ${ }^{c} \quad$ A. Luque ${ }^{c, d}$ Oriol Juan-Babot ${ }^{d}$

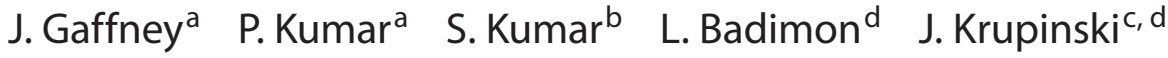 \\ ${ }^{a}$ School of Biology, Chemistry and Health Science, Manchester Metropolitan University, and ${ }^{b}$ Department \\ of Pathology, Medical School, Manchester University and Christie Hospital, Manchester, UK; ' Department of \\ Neurology, Stroke Unit, University Hospital of Bellvitge (HUB) and IDIBELL, and ${ }^{\mathrm{d}}$ Instituto Catalán de Ciencias \\ Cardiovasculares, ICCC-CSIC-HSCSP_UAB, Barcelona, Spain
}

\section{Key Words}

Atherosclerosis $\cdot$ Plaques $\cdot$ Stroke $\cdot$ Heart disease

\begin{abstract}
Formation of unstable plaques frequently results in atherothrombosis, the major cause for ischaemic stroke, myocardial infarction and peripheral arterial disease. Patients who have symptomatic thrombosis in one vascular bed are at increased risk of disease in other beds. However, the development of the disease in carotid, coronary and peripheral arteries may have different pathophysiology suggesting that more complex treatment protocols may have to be designed to reduce plaque development at different locations. In this review we describe the known risk factors, compare the developmental features of coronary and carotid plaque development and determine their association with end-point ischaemic events. Differences are also seen in the genetic contribution to plaque development as well as in the deregulation of gene and protein expression and cellular signal transduction activity of active cells in regions susceptible to
\end{abstract}

thrombosis. Differences between carotid and coronary artery plaque development might help to explain the differences in anatomopathological appearance and risk of rupture.

Copyright $\odot 2008$ S. Karger AG, Basel

\section{Introduction}

Atherothrombosis is the major causative agent for ischaemic stroke (IS), myocardial infarction (MI) and peripheral arterial disease (PAD). Patients having symptomatic thrombosis in one vascular bed are at increased risk of disease in other beds [1]. Patients presenting with cerebral ischaemic events have a 5-year risk for MI of 10$25 \%$ and for non-stroke vascular death of $10-15 \%$ [2]. The risk of a second atherothrombotic event is increased after the occurrence of a first MI or stroke. A second MI occurs

\section{Slevin and J. Krupinski contributed equally to this paper.}

\section{KARGER}

Fax +41613061234 E-Mail karger@karger.ch www.karger.com
(C) 2008 S. Karger AG, Basel

$1015-2008 / 08 / 0754-0209 \$ 24.50 / 0$

Accessible online at:

www.karger.com/pat
Dr. Jerzy Krupinski

Department of Neurology, Hospital Universitari de Bellvitge

Feixa Llarga s/n

ES-08907 Hospitalet de Llobregat, Barcelona (Spain)

Tel. +34 9326077 11, Fax +34 9326078 82,E-Mail krupinski@csub.scs.es 
Table 1. Common and different features in coronary and carotid artery disease

\begin{tabular}{|c|c|c|}
\hline & Coronary artery disease & Carotid artery disease \\
\hline $\begin{array}{l}\text { Risk factors } \\
\quad \text { (over } 300 \text { identified) }\end{array}$ & $\begin{array}{l}\text { cumulative effects: hypertension, smoking, diabetes, } \\
\text { hypercholesterolaemia }\end{array}$ & $\begin{array}{l}\text { cumulative effects: age, smoking, hypertension and } \\
\text { hypercholesterolaemia }\end{array}$ \\
\hline Age of formation & $<40$ years & men $>40$ years; women postmenopause \\
\hline Shear stress & $\begin{array}{l}\text { complex effect on coronary arteries because of local } \\
\text { anatomical differences, i.e. curvature, collateral flow }\end{array}$ & mainly in the carotid bifurcation area \\
\hline $\begin{array}{l}\text { Mechanisms of } \\
\text { symptomatic disease }\end{array}$ & acute thrombosis & $\begin{array}{l}\text { acute thrombosis, haemodynamic stroke, lacunar stroke, } \\
\text { arterial-arterial thromboembolism }\end{array}$ \\
\hline Severe angiographic stenosis & rarely results in $\mathrm{MI}$ & frequently results in stroke \\
\hline Small plaque & often symptomatic, lipid rich & rarely symptomatic, intimal hyperplasia \\
\hline Large occluding plaque & fibrotic, stable & ulcerated, lipid rich, unstable \\
\hline Thrombus & main cause of occlusion & rare cause of occlusion, usually small intramural thrombi \\
\hline Plaque ulceration & thrombus release, acute event & chronic, small microemboli on the surface, rarely acute event \\
\hline Calcifications & in $5-10 \%$ & in $50-60 \%$ \\
\hline
\end{tabular}

within 6 years of the first in $23 \%$ of men and $31 \%$ of women. Within 6 years of a first MI, IS occurs in $9 \%$ of men and $18 \%$ of women. The risk of a recurrent stroke within 1 year of an initial stroke is $10-12 \%$ [3] and the risk of MI is $7 \%$ [4]. These risks are 5-10 times higher than those for the general population and furthermore, patients with mural plaques and accelerated platelet aggregation, even when asymptomatic, have a poor prognosis $[5,6]$. Common and different features in coronary and carotid artery disease are discussed and some more important aspects are listed in table 1.

\section{Coexistence of Coronary Artery Disease and Carotid Artery Disease}

Many studies have shown a relationship between coronary artery disease (CAD) and carotid artery disease. In the majority of patients suffering from IS, significant CAD is also present. For example, clinical trials have shown that $20-30 \%$ of subjects with ischaemic heart disease also had carotid stenosis of greater than $50 \%$ whilst prior PAD and cerebrovascular disease were shown to be independent and strong predictors of adverse outcome in patients with acute coronary syndromes [7]. The Framingham study indicated that multivascular atherosclerosis reduced the life expectancy of patients: after an initial MI, life expectancy was 13.9 years; after an initial stroke, 8.8 years, and in patients with PAD who later suffered MI or stroke, life expectancy was reduced to 1.51.8 years. The prevalence and severity of extracoronary atherosclerosis in 728 patients ( 572 men and 156 women; average age 59 years) referred for coronary angiography and with a history of coronary disease for at least 2 years were assessed by ultrasonography. This population was divided into three groups: group 1, 115 patients without lesions determined by coronary angiography; group 2 , 76 patients with mild coronary stenosis, and group 3, 537 patients with at least one severe coronary artery stenosis (including 294 cases of single vessel disease). The authors observed a strong correlation between the presence, severity and diffusion of CAD and ultrasonographic signs of PAD: the frequency increased from $45 \%$ in group 1 to $88 \%$ in patients with triple-vessel disease in group 3. About two thirds of patients in group 3 had carotid or lower limb atherosclerosis and half had atherosclerosis or aneurysm of the abdominal aorta. Similarly, simultaneous disease in all three peripheral arterial territories ranged from $12 \%$ in group 1 to $51 \%$ in group 3. The risk of finding PAD was increased in patients with CAD compared with healthy subjects. In individual peripheral localizations, the risk was 2 -fold in cases of mild coronary disease and 3- or 4-fold in patients with triple-vessel disease in whom the risk of finding at least one severe peripheral lesion was increased 10 -fold. The authors concluded that the prevalence and severity of ultrasonographic peripheral atherosclerosis in documented coronary patients was closely related to the presence, severity and diffusion of the coronary lesions [8].

\section{Risk Factors for Atherosclerosis}

Common major risk factors include age, gender, genetic predisposition, hypertension, hyperlipidaemia, smoking (a significant increase per 10 cigarettes a day), excess alcohol consumption, chronic infection, diabetes 
mellitus, an increase by $30 \mathrm{mg} / \mathrm{dl}$ in LDL cholesterol, an increase above $15 \mathrm{mg} / \mathrm{dl}$ in glucose and elevated fibrinogen levels. A prolonged increase in diastolic blood pressure of $10 \mathrm{~mm} \mathrm{Hg}$ is associated with a 56 and $37 \%$ increase in the incidence of stroke and coronary heart disease (CHD), respectively [9]. The Second National Health and NutritionExaminationSurveyMortalityStudy(NHANES II) also demonstrated that systolic blood pressure was an important predictor of stroke risk for all groups in the population [10]. It is accepted that diabetes is associated with early onset of atherosclerosis. Almost $75 \%$ of type II diabetic patients exhibit CAD. Postprandial blood glucose fluctuation enhances atherosclerotic lesions and exaggerates intravascular thrombogenicity by increased plasminogen activator inhibitor-1 synthesis, activation of protein kinase $C-\beta$, stimulation of matrix proteins and reduced NO-dependent vasodilatation [11]. More recently studies of obesity and central fat distribution showed a relationship with carotid artery wall thickening in middle-aged women. Physical inactivity and unfavourable dietary and lifestyle patterns are related to cardiovascular disease and premature death. The Atherosclerosis Risk in Communities Study (ARC) suggested a beneficial relationship of physical activity [12]. The Tromso Study revealed sex-dependent protective effects of physical activity in men [13]. The Study of Health in Pomerania (SHIP) demonstrated that physical activity and optimal diet are associated with reduced risk of early carotid atherosclerosis in subjects who never smoked [14]. Serum homocysteine level is a graded risk factor for the incidence of stroke and for the degree of carotid atherosclerosis and also for the incidence of MI; however, the precise relationship with the severity of atherosclerosis in coronary patients is not known. The highest levels of homocysteine were present in patients with both coronary disease and another symptomatic location of atherosclerosis. A small gradient in the extent of coronary atherosclerosis was found with increasing levels of homocysteine. The presence of both hypertension and hyperhomocysteinaemia was associated with more severe coronary atherosclerosis [15]. Further, adverse cardiac events are the consequence of a molecular chain reaction at the site of a vulnerable plaque. Key factors are alterations in platelets and coagulation factors that are activated causing arterial obstruction. Thrombin plays a central role in the development of restenosis and atherosclerosis [16]. Patients with carotid lesions at high risk of thrombo-embolism have more D-dimer than those with normal intima-media thickness (IMT) [17]. D-dimer mean levels are increased in patients with MI, history of stroke and increase gradu- ally in patients with progressing peripheral atherosclerosis.

Liapis and Paraskevas [18] studied the influence of various risk factors on the development of recurrent carotid stenosis after endarterectomy. The cumulative recurrent stenosis rate following carotid endarterectomy was $21.6 \%$ at 10 years of follow-up. The presence of CAD was associated with an increased risk of restenosis, while echogenic plaques and hypercholesterolaemia were associated with a lower risk.

\section{LDL/HDL Levels in the Different Atherosclerotic Diseases}

Plasma lipoprotein concentration is of importance in the development of atherosclerosis [19]. The independent association of high levels of LDL and low levels of HDL cholesterol with coronary atherosclerosis is well established [20]. A longitudinal study of a cohort of 16,209 men over 21 years found serum cholesterol, height and glucose concentration were independently associated with cerebral infarction [21]. Only relatively high cholesterol concentrations are associated with significantly increased risk [22]. There is evidence that elevated cholesterol levels, in association with high blood pressure and smoking, have cumulative effects on carotid stenosis (Framingham heart study with odds ratio 1-10 for moderate carotid stenosis for each $10 \mathrm{mg} / \mathrm{dl}$ increase in cholesterol levels). Recent studies found IS was correlated positively with LDL and negatively with HDL cholesterol levels in plasma. Previous research showed a greater elevation in apolipoprotein $\mathrm{B}$ (apoB) levels than in LDL cholesterol in CAD. The ARC study in a population of 7,261 men and women free of cardiovascular symptoms evaluated the association between fasting plasma LDL, HDL cholesterol, apoB, apolipoprotein A-I (apoA-I), triglycerides, HDL density subfractions and IMT in extracranial carotid arteries measured using ultrasound imaging. A CAD group was selected for comparison. Lipid factors showed an approximately linear association with carotid thickness: positive for LDL and plasma apoB and negative for HDL and apoA-I levels. Apolipoproteins and HDL density subfractions did not contribute to the association after accounting for LDL and HDL cholesterol. Compared with control subjects, those whose carotid thickness exceeded $0.9 \mathrm{~mm}$ had a greater proportional elevation in LDL than in apoB, whereas HDL reductions were small. CAD subjects showed greater elevation of apoB than LDL cholesterol. Although the lipid profiles 
associated with asymptomatic carotid wall thickening and stenotic coronary disease are similar, the differences found suggest that LDL is the most important lipid factor in earlier stages of atherogenesis, whereas the metabolism of triglyceride-rich lipoproteins and its effects on LDL and HDL may be more relevant to later atherothrombotic stages. The patients with multivessel disease who did not use lipid-lowering therapy had a 50\% increase in the thickness of the carotid intima media $(\mathrm{p}=0.030)$ and a $41 \%$ higher oxidized LDL:LDL ratio $(\mathrm{p}=0.020)$ than those with healthy vessels. Furthermore, patients with multivessel disease on statin therapy had a $24 \%$ lower oxidized LDL:LDL ratio than those who did not use lipidlowering drugs $(p=0.027)$, although the concentration of LDL cholesterol did not differ between the groups. This study supports the hypothesis that lipid oxidation plays a role in the development of atherosclerosis [23].

It has been suggested that immune responses against oxidized LDL activate and regulate the inflammatory processes that accompany all stages of atherosclerosis [24]. Clinical trials have found a beneficial effect associated with a reduction of triglyceride-rich lipoproteins in plasma, leading to a reduction in the progression of coronary atherosclerosis and coronary events $[25,26]$, but no beneficial influence on carotid atherosclerosis and cerebral events has been demonstrated. Lipid-lowering therapy has a beneficial effect on the incidence of MI and stroke without a major change in plaque size or volume [27].

The difference in pathogenesis underlying the two diseases probably contributes to this, since overlying thrombosis is the major causative factor in MI: IS involves numerous factors, including thrombosis from an atherosclerotic plaque in an extracranial or intracranial vessel, small-vessel disease in the brain and inflammatory arterial disease.

\section{Is IMT a Predictor of Future Vascular Events in Coronary or Carotid Arteries?}

The IMT of the arterial wall, measured by B-mode ultrasonography in carotid and common femoral arteries, is related to atherosclerosis. Recent studies confirm that two markers of preclinical atherosclerosis, carotid IMT and waist-to-hip ratio were significant and independent predictors of carotid wall thickness [28]. The prevalence and degree of IMT in the carotid arteries have been related to risk factors for cardiovascular disease [29], and the prevalence of symptomatic CHD in cross-sectional studies, and to the risk of development of CHD in cohort studies of symptomatic normal subjects [30]. Held et al. [31] reported data on a subgroup of more than 500 patients with stable angina in which IMT, lumen diameter and the presence of atherothrombotic plaque was assessed in the carotid artery using ultrasound. These assessments were related to the risk of MI or coronary vascular death and the requirement for coronary revascularization during a median follow-up of 3 years. After adjustment for other risk factors, the degree of carotid IMT was only a weak predictor of subsequent coronary events, whereas the presence of carotid plaque was a strong significant predictor in this study.

There is a positive association between carotid artery IMT and the incidence of new MI and stroke in adults 65 years of age or older who did not have a history of cardiovascular disease. Furthermore, risk gradients for MI and cerebral stroke are similar [32]. When statistical adjustment was made for traditional cardiovascular risk factors, carotid artery IMT remained a significant predictor of cardiovascular events. The strength of the associations between IMT and outcome was at least as strong as associations seen with traditional risk factors. Thus, the IMT of the common carotid and the internal carotid arteries is strongly associated with the risk of MI and stroke in asymptomatic older adults. Other arteries, especially medium-sized ones such as the brachial and superficial femoral arteries, do not present so clear a relationship with atherosclerosis progression, suggesting some local differences in pathology.

Mack et al. [33] examined the correlation between changes in both carotid artery IMT and CAD. Measures obtained by carotid ultrasonography and coronary angiography showed a significant correlation, although they each assessed different aspects of the atherosclerosis process. Sen et al. [34] investigated the relationship between aortic and carotid atherosclerosis, and studied the effects of coronary risk factors for these arteries. Significant correlations between maximal aortic wall thickness (MAWT) and aortic wall volume (AWV) with carotid IMT were demonstrated. MAWT, AWV and IMT were significantly higher in patients with CAD compared with controls. MAWT, AWV and IMT had positive correlations with age, systolic blood pressure and triglyceride levels, and a negative correlation with high-density lipoprotein cholesterol. This study demonstrated that both aortic and carotid atherosclerosis was closely correlated with coronary atherosclerosis, and that the atherosclerosis indices are independently associated with age and hyperlipidemia. 
Carotid arterial IMT measured by high-resolution Bmode ultrasonography is used as a non-invasive surrogate end point to measure progression of atherosclerosis. However, there are no detailed data on the relationship between aggregation of coronary risk factors and carotid atherogenesis. In the Cholesterol Lowering Atherosclerosis Study, significant correlations between change in common carotid artery IMT and quantitative coronary angiographic measures of change were evident over all coronary artery lesions, and in mild/moderate $(<50 \%$ diameter stenosis), but not severe ( $\geq 50 \%$ diameter stenosis) coronary artery lesions. In mild/moderate lesions the correlations with change in common carotid IMT were: the $\%$ diameter stenosis, minimum lumen diameter, and vessel edge roughness. While measures obtained by carotid ultrasonography and coronary angiography were correlated, they each assessed different aspects of atherosclerosis [35]. The GENIC case-control study showed that an increased common carotid artery IMT was associated with stroke and may help predict patients at high risk of stroke [36]. Few studies have determined whether carotid artery IMT is associated prospectively with risk of first IS. In the ARC study, carotid IMT, an index of generalized atherosclerosis, was defined as the mean of IMT measured by B-mode ultrasonography at six sites in the carotid arteries. The strength of the association was reduced by the inclusion of putative stroke risk factors, but it remained elevated at higher IMTs. Hence, mean carotid IMT is a non-invasive predictor of future IS incidence [37].

Increased carotid IMT and coronary artery calcification (CAC) are used as markers of early atherosclerosis. In young adults, there is an association between increased carotid IMT and CAC and other cardiovascular risk factors. Carotid IMT in addition to CAC may provide a means to identify young adults with premature atherosclerosis. Few studies were population-based and furthermore little attention has been given to the influence of CHD risk factors on IMT in populations at low risk for CHD. Authors found thinner IMT than those in highrisk populations, suggesting that an increased IMT might reflect local atherosclerosis [38]. Protective factors such as HDL cholesterol or regular and moderate alcohol consumption are probably important determinants of the early stages of atherosclerosis in these low-risk populations [39].

Other risk factors displaying statistically significant correlations with mean carotid IMT were tissue polypeptide antigen level and activity, plasminogen activator inhibitor-1 antigen level and level of HDL cholesterol. The significant association between carotid IMT and CHD suggests that carotid and coronary atherosclerosis evolve simultaneously. Hence carotid IMT can be used as a predictor of coronary atherosclerosis.

\section{Atherosclerotic Plaque Pathology}

What is uncertain is whether atherosclerotic plaques are diverse in their structural, cellular and molecular characteristics. Recent studies suggest that carotid artery atherosclerosis is a symmetrical disease, particularly in the degree of calcification [40] and inflammation [41]. However, this symmetry in patients undergoing endarterectomy with advanced disease is not so clear, suggesting that local anatomy, flow conditions and risk factors may determine unilateral plaque progression.

\section{Appearance and Structure of Coronary Plaques}

Stable angina is associated with smooth, fibrous coronary artery plaques, whereas unstable angina, acute MI and sudden cardiac death are invariably associated with irregular or ruptured plaques [42]. Evidence from a prospective angiographic study suggested that severe stenoses progressed to total occlusion about 3 times more frequently than less severe lesions, but this process infrequently resulted in MI [43]. In contrast, most of the severe carotid stenoses led to cerebral infarction. These findings support the hypothesis that disruption of small plaques is important in the pathogenesis of acute MI, whereas longstanding severe stenosis more commonly results in total vessel occlusion with a small or silent infarction, perhaps because of the presence of well-developed collateral vessels. In the coronary arteries, small plaques tend to be lipid-rich and prone to disruption. Markedly stenotic plaques tend to be fibrotic and stable [44]. The most important contributors to coronary plaque disruption are morphology, lipid composition, presence of foam cells and stresses across the vessel wall [45]. Foam cells can secrete large amounts of procoagulant tissue factor (TF) [46] that stimulate thrombus formation in contact with blood [47]. Atherosclerotic plaque rupture with atheromatous debris; distal embolization is dependent on plaque composition rather than plaque burden. Features of vulnerability are: a large lipid core, a thin fibrous cap and an inflammatory filtrate rich in monocytes and macrophages [48]. Studies of ruptured plaques indicate that 
large necrotic cores, a fibrous cap of less than $65 \mu \mathrm{m}$ in thickness, intraplaque haemorrhage and infiltrating macrophages within the cap are indicators of instability [49-51].

\section{Events Leading to Coronary Plaque Rupture}

The cellular events leading to plaque rupture are not fully understood. Recruitment of T lymphocytes within the atheroma was increased at the site of future rupture. $\mathrm{T}$ lymphocytes are the source of interferon- $\gamma$ that markedly decreased the ability of human smooth muscle cells to express interstitial collagen genes [52]. This provides a mechanism to explain impaired maintenance and repair of the collagenous meshwork in vulnerable plaques, rendering it weak and prone to rupture. In addition, accelerated degradation of collagen and other matrix components may contribute to weakening of the fibrous cap. Increased activity of matrix metalloproteinases (MMPs) has been demonstrated during atherosclerotic plaque disruption [53]. MMPs may modify the extracellular matrix and promote stabilization by promotion of smooth muscle cell mitogenesis, or alternatively, destabilize vulnerable plaques by promoting matrix destruction, angiogenesis, leucocyte infiltration and apoptosis [54, 55]. Although these mechanisms probably play a prominent role in plaque rupture, other factors may also contribute to the unstable coronary syndrome. There is impaired responsiveness to endothelium-dependent vasodilators in diseased portions of human coronary arteries [56] that may contribute to impaired flow in these vessels, particularly at sites of underlying stenoses. The precipitating event in most cases of acute MI involves thrombotic occlusion of the vessel, usually at sites of plaque disruption.

\section{Appearance and Structure of Carotid Plaques and Factors Associated with Rupture and Thrombosis}

Endothelial dysfunction and changes in arterial wall morphology including thickening of the tunica intima, excess synthesis of the collagenous matrix (fibroblastic intimal thickening) and permanent or dynamic deposition of lipids (fatty streaks) occur in childhood. Definite atherosclerotic plaques in the carotid arteries are usually not evident before the menopause in women or the age of 40 years in men. Long-term exposure of the vessel wall to risk factors is required to overcome the highly effective defence mechanisms that are not yet fully understood.
Because of vascular remodelling, lumen obstruction is compensated for by widening of the vessel. For stenosis to develop, plaques must evolve into complicated lesions characterized by small ruptures and consecutive mural thrombotic episodes. This process commonly starts with small- to medium-sized plaques. Potential determinants of plaque rupture are the composition of the lesion (large lipid-rich core), damage to the fibrous cap and haemodynamic stress. Based on pathological studies, plaque fissuring is a frequent event, while the formation of overlying large thrombi (with progression of stenosis or vessel occlusion) is rare (fig. 1). These data emphasize the significance of local and systemic thrombus-promoting factors. The risk profile of advanced atherogenesis includes markers of enhanced prothrombotic capacity, attenuated fibrinolysis and clinical conditions associated with defective coagulation. Almost all patients with more than three procoagulant risk conditions had carotid stenosis or showed progression of pre-existing stenosis during a 5 -year period [57]. Indeed, diabetic patients with unstable carotid disease measured by the presence of symptomatic carotid disease, plaque echogenicity on ultrasound, or plaque vulnerability as evidenced by ulceration on histology have significantly higher levels of markers of haemostasis, fibrinolysis and plaque remodelling [58]. In a recent study, $63.1 \%$ of patients had carotid plaque progression and the combined 5-year adjusted risk of stroke, MI and vascular-associated death was $15.7 \%$ [59].

Atherosclerotic plaque irregularity and rupture of the carotid artery are closely associated with the occurrence of cerebral ischaemic events [60]. Patients with irregular or ulcerated plaques determined by carotid angiography have a higher risk of IS irrespective of the degree of stenosis of the vessel lumen [61]. The incidence of vessel-tovessel embolism from the carotid territory is about 5.2\% in both extracranial carotid artery stenosis and middle cerebral artery stenosis [62]. Furthermore, systemic factors, such as infection, autoimmune disease, or genetic predisposition might be partly responsible for plaque instability and rupture [63].

If plaque stability is modulated by systemic factors, then plaque morphology at one site might predict plaque morphology at a distant site. A study of carotid bifurcation angiograms from patients with a recent symptomatic carotid stenosis determined the extent to which plaque surface irregularity and ulceration at one site (the symptomatic carotid artery) was associated with irregularity and ulceration at a distant site (the contralateral carotid artery) and the extent to which plaque morphol- 

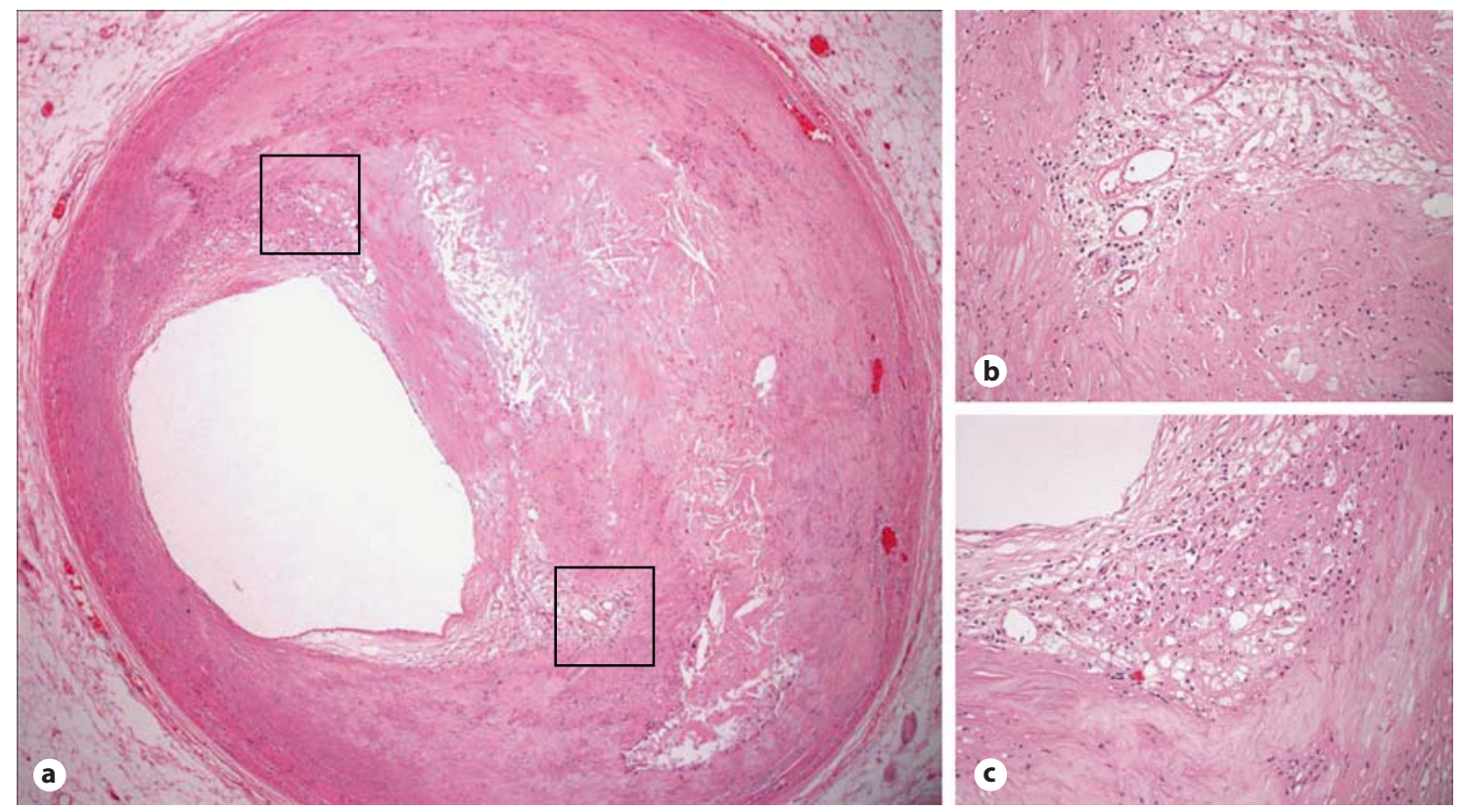

Fig. 1. a Section through the coronary artery taken from a 61-year-old male patient who was diabetic with hypercholesterolaemia and who suddenly died after MI. ×40. It shows advanced type V lesion, according to AHA classification, with important stenosis of the lumen. Angiogenesis is usually seen in the areas with important inflammation. New vessel formation can be seen within the necrotic core (inset $\mathbf{b}$ ) or within the fibrous cap (inset c). b, $\mathbf{c} \times 200$.

ogy at these sites was associated with previous MI and subsequent non-stroke vascular death (due mainly to CAD) [64]. Furthermore, patients with plaque surface irregularity or ulceration in the symptomatic carotid artery were twice as likely as those with a smooth plaque to have irregular or ulcerated plaque in the contralateral carotid artery. Patients with irregular or ulcerated plaques in one or both carotid arteries were more likely to have had a previous MI than patients with smooth plaques and were more likely to suffer a non-stroke vascular death on follow-up. These findings suggest that some individuals have a systemic predisposition to plaque growth, irregularity and rupture that is independent of recognized vascular risk factors.

Increased lymphocyte concentration, macrophage accumulation, dysregulated nitric oxide metabolism, tumour necrosis factor- $\alpha$, MMPs, adhesion molecules, phospholipases, autoimmunity, multiple infections, proliferating smooth muscle cells, intraplaque haemorrhage, extensive vascularization of the plaque and apoptosis may contribute to symptomatic carotid disease (fig. 2). However, it is uncertain what link exists between cytokines produced during plaque formation, circulating sol- uble cytokines in serum and their concentration in the areas of surviving cerebral penumbra.

Studies of carotid plaques have demonstrated the presence of significant numbers of inflammatory lymphocytes, and autoimmunity may be involved during atherogenesis. Irvine et al. [65] demonstrated that plaques with $>70 \%$ stenosis from asymptomatic and symptomatic patients had higher expression of platelet-derived growth factor and receptors and more macrophages and intraplaque haemorrhage than plaques with $<70 \%$ stenosis.

\section{Relationship between Plaque Constituents and Occurrence of Symptomatic Disease}

Controversy exists as to the relationship between plaque composition and the development of neurological symptoms. Studies of a long series of patients with carotid stenosis showed that the extent of stenosis was not correlated with symptoms and was unaffected by the morphology of the plaque [66]. This, however, suggests that plaque morphology may independently have a role 

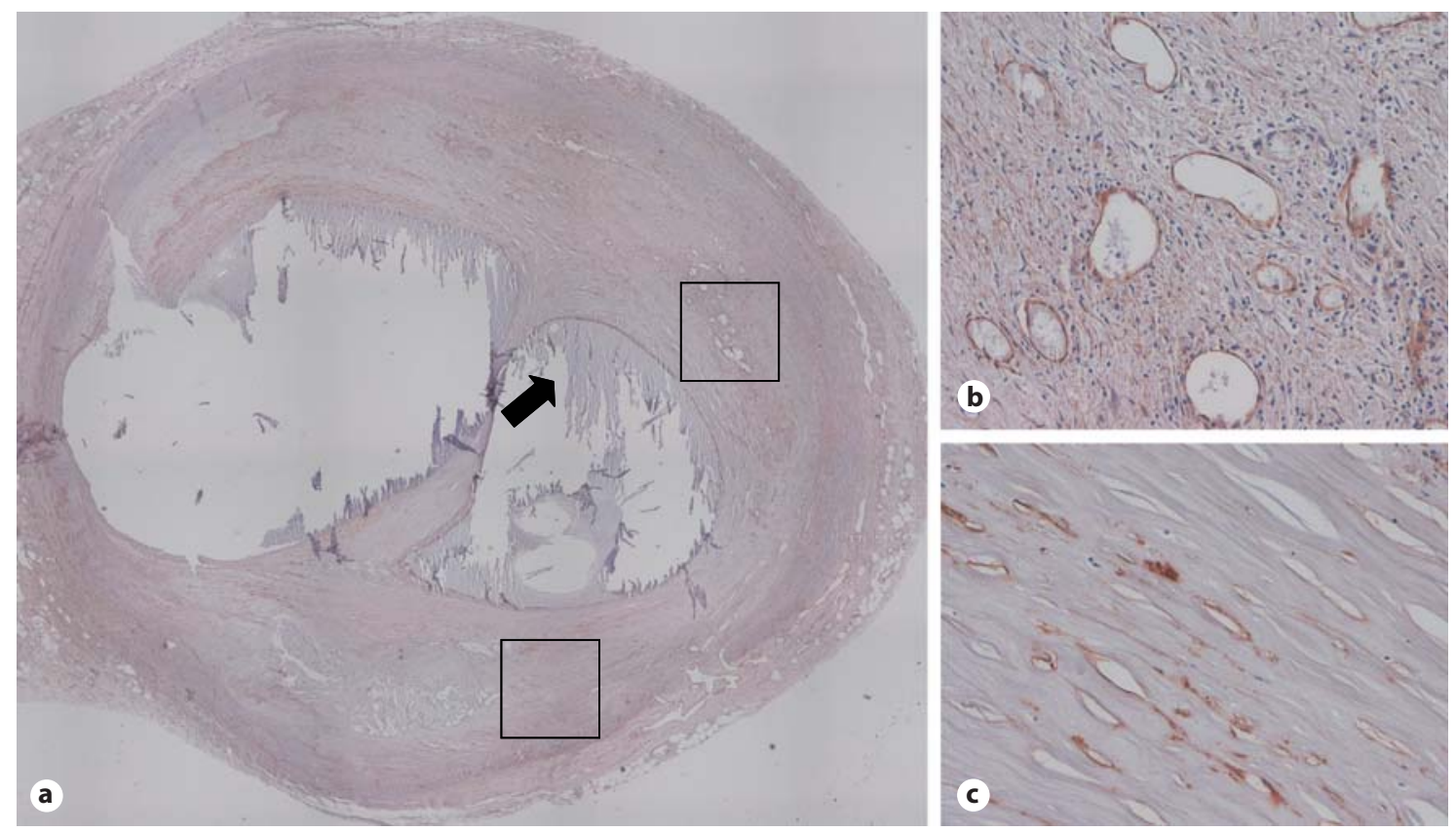

Fig. 2. a Advanced carotid lesion, type V, taken from 67-year-old diabetic patient without history of cardiovascular disease who died of septic shock. $\times 40$. Carotid lesions as compared to coronary are usually more heterogenous, with less lumen stenosis, with important calcification (arrow), prominent lipidic core early surface asymptomatic rupture and intraplaque hemorrhage. Angiogenesis is also abundant in the various areas of the plaque showing newly formed blood vessels. New vessels are formed close to inflammatory areas (inset $\mathbf{b}$ ), as well as in the areas with a very limited number of inflammatory cells (inset $\mathbf{c}$ ). b, $\mathbf{c} \times 200$; immunostaining with antibody against CD105; 1:100; Endoglin, R\&D Systems.

in the presentation of carotid disease. Intraplaque haemorrhage, lipid levels and necrosis seem to be more common in plaques causing high-grade symptomatic stenosis $[67,68]$. A significant correlation between plaques containing amorphous material mixed with cholesterol and neurological symptoms was reported by Feeley et al. [69]. Interestingly, the amount of fibrous tissue found in asymptomatic patients was higher than in patients experiencing increasing numbers of ischaemic events. Other plaque features like foam cell infiltration in the fibrous cap, thinning or rupture of the cap, lipid-rich cores beneath the cap, cholesterol crystals and necrosis are associated with progression of atherosclerotic disease and neurological symptoms [70]. Leen et al. [71] found that an eosinophilic amorphous material mixed with cholesterol was the predominant nonfibrous component in symptomatic plaques. However, in an earlier study of Golledge et al. [72], carotid plaque morphology, plaque surface features as well as visualization by echolucency of the plaque did not distinguish between patients who presented with stroke without warning and symptomatic patients (ex- hibiting TIA, amaurosis fugax, crescendo TIA, stroke with warning). Liapis et al. [73] studied the impact of the carotid plaque type on recurrent carotid stenosis, future cardiovascular events and patient survival. Hypertension, $\mathrm{CAD}$, and echolucent plaques were associated with a higher incidence of cardiovascular events. Patients undergoing endarterectomy for symptomatic disease with ulcerated complicated carotid plaques had higher intraplaque D-dimer levels. Furthermore, hypercholesterolaemic patients with ulcerated complicated plaques had significantly higher fibrin turnover indicating greater plaque procoagulant activity and risk for symptomatic disease [74]. Markers of plaque remodelling may be related with the occurrence of symptomatic disease. In situ zymography established that unstable carotid plaques (estimated by clinical and morphological methods) had higher MMP activity. This suggests that MMPs definitively contribute to plaque remodelling and possibly contribute to symptomatic carotid disease. Further, patients with prior history of CAD had higher MMPs activity independently of any other risk factor. This suggests that remodelling 
properties of MMPs may be similar in both coronary and carotid diseases. Interestingly, patients with asymptomatic carotid disease, but with plaque progression within the last year prior to endarterectomy had higher intraplaque MMP-8 activity than patients without progression. Patients with hypertension had higher intraplaque MMP-8 activity, further linking this MMP with the most frequent risk factor in patients with symptomatic carotid disease [75].

\section{Plaque Rupture: a Comparison of Coronary versus Carotid}

Rupture-prone high-risk coronary plaques, in particular, are thought to consist of a thin fibrous cap covering an atheromatous lipid-rich core containing cholesterol and its esters [76]. Recent studies have suggested that plaque morphology and biomechanical stresses should be considered. In vivo magnetic resonance imaging can be used to predict stress within plaques and showed greater stress in symptomatic than asymptomatic patients, with an increased rupture risk [77]. Indicators of plaque rupture may be intrinsic stresses (i.e. the continued accumulation of lipoproteins from plasma with or without uptake by macrophages to form foam cells) or extrinsic flow-dependent stresses. Leen et al. [71] concluded that cholesterol deposition precedes intraplaque haemorrhage rather than the reverse, indicating that haemorrhage is an effect rather than a cause or pathogenic factor. Gronholdt et al. [68] showed that the extent of haemorrhage in a plaque was positively associated with lipid concentration and negatively associated with fibrous tissue content. An alternative pathogenesis to plaque rupture/intraplaque haemorrhage is bleeding into plaques from thin-walled new vessels originating from the vasa vasorum and commonly found at the plaque base [79]. This bleeding may theoretically increase intraplaque pressure, with resultant cap rupture from the inside.

Intrinsic stresses also include chronic inflammation with degradation of the extracellular matrix weakening the fibrous cap. The cells involved in inflammation are activated macrophages and/or mast cells that by phagocytosis or secretion of proteolytic enzymes [80] degrade collagen, destabilizing the fibrous cap. Smooth muscle cells, on the contrary, stabilize the plaque by secreting collagen [81]. Plaque rupture may lead to intraplaque haemorrhage, formation of superimposed thrombosis, embolism, and subsequent neurological symptoms.
In contrast, carotid plaques seem to undergo slow rupture over many years and often remain asymptomatic. However, local ulceration increases the risk of focal microthrombi formation and subsequent thrombosis with silent infarction or slow formation of distal and later occlusive thrombi. Carotid plaques appear by histology to be more advanced and present a more mixed pathology. Even in plaques at sites where erosion predominates, focal ulceration occurs with surface thrombi formation. This probably explains why carotid plaque rupture is not as acute a clinical syndrome as is the case of coronary plaques.

\section{Thrombus Formation Precedes Acute Cardiovascular/Cerebrovascular Events}

Thrombus formation plays a fundamental part in the development of acute coronary syndromes. Angiographic, pathological, and biochemical data implicate the formation of a thrombus overlying a rupture in the lining of the plaque in the pathogenesis of unstable angina. Subclinical episodes of plaque disruption with local thrombin activation and subsequent healing may represent a major pathway for progression of atherosclerotic lesions. Pathological studies have shown repeatedly in humans and in experimental animals that growth of an atherosclerotic plaque occurs by outward, abluminal expansion [82]. This phase of growth may last for years, and only after the plaque burden occupies half of the luminal area does the plaque protrude into the lumen, becoming visible by angiography and capable of impairing blood flow. This suggests that angiography visualizes the lumen rather than the plaque itself and may underestimate plaque size.

In transmural MI occlusive thrombi develop in a protracted and recurring manner, which is reflected in their layered appearance [83]. Based on autopsy studies, 85\% of occlusive thrombi are rich in fibrin and erythrocytes and the remaining $15 \%$ are pure platelet thrombi containing little or no fibrin [84]. The phenomenon of distal appositioning beyond the site of plaque rupture was found in $50 \%$ of cases of fatal infarction, whilst proximal apposition was seen in $25 \%$ of cases. Thrombus formation and platelet deposition is 6 times higher on the lipidrich core than on other arterial wall components [85]. The nature of the plaque component exposed by rupture determines the degree of its activation, i.e. external coagulation pathway, thrombin activation, fibrin deposition and platelet activation [86]. TF is a key molecule in 
the coagulation and previous studies have demonstrated that increased expression of TF in high-grade carotid stenosis is associated with plaque destabilization, clinically evidenced by both a history of previous ischaemic symptoms and the detection of micro-emboli in longterm transcraneal Doppler ultrasonography monitoring of the ipsilateral middle cerebral artery [87]. Further, active carotid plaques (rich in inflammatory cells) were found to express abundantly TF. Blood-borne TF activity prior to endarterectomy predicts cerebrovascular and peripheral vascular disease events at 1 year in elderly patients subjected to endarterectomy for high-grade carotid stenosis [88].

\section{Plaque Calcification}

The precise process of calcification in plaques is still unclear. Coronary plaque calcification accounts for only $5 \%$ of acute coronary syndromes [89]. Calcification increases in plaques with age and the overall plaque burden, but not with the degree of stenosis in coronary arteries [90]. Calcium seems to stabilize the plaque, preventing disruption and thrombosis. Calcium is found less frequently in lesions responsible for unstable angina and $\mathrm{MI}$ [91]. CAC reflects the extent of coronary artery arteriosclerosis but the extent of CAC is not well described in older adults. Overall, CAC scores were increased in subjects with clinical cardiovascular disease or evidence of subclinical cardiovascular disease rather than those with no evidence of disease. Older adults with evidence of clinical or subclinical CAD had higher total CAC scores. Though the extent of CAC was lower in those with minimal evidence of CAD, the range was broad and not explained by CAD risk factors.

There is uncertainty over carotid artery calcification and the risk of neurological events. The presence of calcification is a frequent event in carotid plaques, especially those with mixed histology. In recent studies 13\% of patients presented lamellar bone formation, which was correlated directly with the presence of sheet-like calcifications. Bone formation occurred in heavily calcified carotid lesions devoid of ulceration and haemorrhage, and patients with extensive calcification of the carotid plaques were less likely to have symptomatic disease [92]. Determination of the extent of calcified carotid plaques may be useful to improve the predictive value of risk factor-based multivariate models. In one study calcified plaques of carotid arteries were significantly correlated with coronary artery stenosis, hypercholesterolaemia, increasing age, diabetes, hypertension, and left ventricular hypertrophy in contrast to smoking status, body mass index and male sex [93].

\section{The Importance of Plaque Stability}

The morphological stability of carotid arterial plaques correlated significantly with coronary artery stenosis. Morphologically unstable plaques of the carotid artery were able to predict unstable forms of coronary obstruction with a sensitivity of $68 \%$, specificity of $85 \%$, predictive power of $72 \%$ and a likelihood ratio of 4.5 [94].

\section{Extrinsic Factors, Shear Stress and Haemodynamics}

Extrinsic stresses on a plaque are haemodynamic forces (i.e. shear stress, a sudden increase in blood flow, blood pressure, and pulse rate) acting on the weak shoulders of the cap. In particular, mechanical stresses of flowing blood on the vessel wall are important stimuli that influence atherogenesis by regulating endothelial function, smooth muscle cell behaviour, and the interactions of endothelium with other circulating components [57]. The carotid plaque is typically situated in the bifurcation of the artery, where a mismatch in flow impedance, abnormal wall tension, and non-laminar turbulent flow may predispose to further atherogenesis and eventually to plaque rupture. Superimposed thrombosis can also grow on an intact plaque if hyperthrombogenicity exists because of platelet activation, hypercoagulability, and/or impaired fibrinolysis [95]. Pulsatile blood flow through coronary arteries is an important regulator of the structure and function of these vessels and is implicated in the pathogenesis of atherothrombosis. In the large epicardial coronary arteries, atherothrombosis localizes to the outer wall of one or both daughter vessels at major bifurcations. However, in the coronary vasculature, flexing of the vessels because of cardiac contractions introduces a complication. Even more problematic are the effects of curvature of these vessels as they cross the surface of the heart, as curvature can introduce substantial effects on shear. In the coronary arteries, flow-induced alterations can also affect the development of collateral supply. In consequence, haemodynamics leads to pathological arterial remodelling and may significantly affect progression of both coronary and carotid diseases. 


\section{Inflammation and Atherosclerosis}

Chronic or recurrent infections, particularly with Chlamydia pneumoniae, Cytomegalovirus, Heliobacter pylori and peridontal infections have been observed in patients with atherothrombosis in the cardiac, cerebral and lower extremity circulations [96]. CD4+ T cells reactive with Chlamydia proteins have been cloned from human lesions, and CD8+ T cells also present, recognize viral antigens and may result in death of arterial cells and acceleration of atherosclerosis [97]. Peptidoglycan, a major component of the cell wall of gram-positive bacteria, abundantly present in all human mucosa has been observed in atherosclerotic arteries in association with the vulnerable plaque phenotype. Peptidoglycan binds to CD14 on macrophages and induces pro-inflammatory cytokine and metalloproteinase synthesis [98]. Human atheromatous plaques taken from aorta, coronary, and carotid arteries contained dendritic cells, which may mediate autoimmune responses during plaque evolution. These atheromas were positive for DC-SIGN antigens, which mediate adhesion to T lymphocytes and endocytosis [99]. Lipid-rich atherosclerotic plaques have elevated activity of pro-inflammatory enzymes, which contribute to plaque rupture. Elevated levels of pregnancy-associated plasma protein (PARP-A), a metalloproteinase, have been found in hyperlipidaemic patients at high risk of cardiovascular events and with echogenic, unstable carotid plaques [100].

The possible mechanism leading to symptomatic vascular disease may be explained by increased coagulation [101], endothelial dysfunction [102], plaque instability $[103,104]$, and increased progression of the plaque due to inflammation [105]. The American Physician's Health Study showed that baseline levels of C-reactive protein (CRP) were significantly higher among subjects who later had an MI or IS than among those who remained free of vascular disease [106-108]. CRP, an acute phase reactant, added important prognostic information to patients suffering from metabolic syndrome in respect of MI, stroke, coronary revascularization and cardiovascular death [109]. A recent study has shown that CRP was a stronger predictor of cardiovascular events than was LDL cholesterol levels [110]. This is important, as in many situations atherosclerosis occurs in the absence of hyperlipidaemia. Increased levels of CRP are associated with a worse outcome in patients with IS, independently of other prognostic factors like fibrinogen [111]. CRP is an effector molecule able to induce and promote atherothrombosis. Endogenous expression of CRP is increased in ac- tive, ulcerated, non-complicated human carotid plaques and recent evidence showing mitogenic capabilities in smooth muscle cells and endothelial cells suggests a possible role in plaque development [112]. Blann and McCollum [113] suggested that von Willebrand factor was the most sensitive marker of peripheral atherosclerosis and that none of the plasma markers were useful indicators of the degree of carotid artery stenosis.

\section{Genetic Predisposition Affects both Coronary and Carotid Atherosclerosis}

Both genetic and environmental factors are implicated in atherosclerosis [114]. Carotid IMT is a quantitative measure of subclinical atherosclerosis and is predictive of subsequent MI and stroke IMT is an adaptive process of the arterial wall, but presumably not always related to atherogenesis. It seems that internal carotid artery IMT might represent focal atherosclerotic plaques and thickening of common carotid artery intima may represent total body atherosclerosis. There is also controversy regarding the variability in IMT explained by genetic factors. In the Framingham Offspring Cohort Study of 1,630 sib-pairs, 38\% of the carotid IMT variability was due to heritable factors [115]. Studies of Mexican descendents living in the USA suggest that carotid IMT is heritable, with estimates ranging from 0.86 to 0.92 . Gender and interethnic differences in intimal thickening, as demonstrated histologically on autopsy material, indicated a strong genetic control on this process. Nanda et al. [116] studied racial differences in thoracic aorta thickness among IS patients and found that black populations have a lower prevalence of extracranial atherosclerotic disease than Caucasians and this difference cannot be explained by the existing risk factors alone.

The genes implicated in carotid IMT variability remain undefined. Some studies point to the T/T genotype of $\beta$-fibrinogen, factor $V$ Leiden, the $\mathrm{D} / \mathrm{D}$ genotype of the angiotensin-converting enzyme (ACE), an insertion/deletion polymorphism and the paraxonase gene [117-119]. An insertion/deletion (ID) polymorphism in the ACE gene has been shown to be an independent risk factor for cardiovascular disease, especially in subjects otherwise at low risk for $\mathrm{CHD}$. The present data suggest that the $\mathrm{ACE}$ gene seems to be a candidate gene that strongly influences IMT of the arterial wall and might therefore be involved in an individual's predisposition to the development of atherosclerosis. 
A common variant in the promoter of the human stromelysin gene, causing reduced enzyme expression, has been associated with the progression of coronary atherosclerosis. On the other hand, increased stromelysin activity may promote plaque rupture. The results demonstrate that polymorphisms in the promoter region of stromelysin are associated with structural and functional characteristics of the common carotid artery in healthy male subjects without major risk factors for atherosclerosis. Individuals with the 6A/6A genotype (associated with lower enzyme activity) show a triad of events, namely increased wall thickness, enlarged arterial lumen, and local reduction of wall shear stress, which might predispose them to atherosclerotic plaque localization [120].

Another genetic predisposing factor is the human serum paraoxonase (PON1) gene. It exists in two polymorphic forms differing in amino acids at positions 192 (glutamine and arginine, $\mathrm{Q}$ and $\mathrm{R}$, respectively) and 55 (methionine and leucine, $\mathrm{M}$ and $\mathrm{L}$, respectively). PON1 protects LDL from oxidation, and if PON1 is inactivated LDL oxidation is increased. Authors compared PON1 isoforms, $\mathrm{Q}$ and $\mathrm{R}$, for the extent of lipid peroxidation in human coronary and carotid lesions. They concluded that PON1 may be anti-atherogenic because it hydrolyzes lipid peroxides in human atherosclerotic lesions [121]. The San Antonio Family Heart Study used carotid artery plaque as a genetic marker of subclinical atherosclerosis. They established that that focal carotid artery plaque is heritable after discounting established cardiovascular risk factors [122].

Human carotid plaques, coronary arteries, aorta and in-stent stenosis specimens were examined for differential gene expression in vascular smooth muscle cells (VSMCs) [123]. Sequencing of difference products identified several genes, the expression of which was increased in primary plaque VSMCs, including IGF-BP2, cartilage link protein, enteric muscle y-actin, $\alpha$-tropomyosin and laminin- $\beta_{1}$. Genes associated with cell proliferation, contraction and cell/matrix signalling were increased in in-stent stenosis versus normal medial VSMCs. Numerous studies pointed at the possible genetic predisposition to have coronary and carotid atherosclerosis. Some candidate genes related to risk of coronary disease or stroke have been already selected. Future studies based on wide-genome association analysis will bring new data.

\section{Gene Expression Analysis of Cardiovascular Disease}

Although it is accepted that genetics contributes to the development of cardiovascular disease, identification of the specific genes involved has been difficult. CAD is a multifactorial disease influenced by both genetic and environmental factors and their interactions [124]. Previously the identification of specific causative genes was a laborious process involving Northern and Western blotting and immunohistochemistry and studying either a single gene or transcript or a maximum 5-50 genes at a time. Identification of the global gene changes and their variants in CAD may allow the development of individual therapies [125, 126]. Microarray analysis is a powerful technique that allows the simultaneous screening of multiple gene transcripts, either the whole genome, using a gene chip, or sections associated with a particular aspect of a disease process [127].

Satterthwaite et al. [128] studied gene expression in CAD and found 361 genes differentially expressed compared to normal artery. These included inflammationassociated interleukin- $1 \beta$ and interleukin- 8 and signal transducer and activator of transcription, IL-6. A much larger study of 12,000 genes in severely atherosclerotic coronary arteries [129] showed upregulation of 55 genes, of which 49 were novel and included genes associated with inflammation (tumour necrosis factor- $\alpha$-induced protein-2), apoptosis (PIM-2 oncogene) and cell migration (VCAM-1). They also found one gene coding for a reducing agent (GST) downregulated. Other studies have tried to identify gene expression in symptomatic and asymptomatic carotid plaques from the same patient and showed that the former overexpressed two genes, CD163 and HO-1 associated with iron-heme homeostasis [130]. Gene profiling has shown that apoptotic genes play a central role in carotid plaque development. For example Martinet et al. [131] found 205 of these genes upregulated and death-associated protein kinase located in foam cells where it contributed to the uptake of LDL.

An alternative approach is to use protein arrays to study changes in protein composition of plaques. Since this a newer technique, currently there are relatively fewer studies. Slevin et al. [132] found proteins associated with apoptosis (caspase-9), DNA repair mechanisms (topoisomerase-II $\alpha$ ) and cell signalling molecules expressed in carotid plaques. Vaisar et al. [133] used shotgun proteomics to show that proteins involved in the metabolism of HDL were associated with CAD. Proteomics has the potential to reveal novel important mediators in- 
volved in the development of unstable atherosclerosis and phosphoprotein arrays will help identify activation of signal transduction cascades.

It appears that rapid advances in genomic tools and techniques (Human Genome Project, International HapMap Project, high-throughput genotyping, among others) will transform our understanding of cardiovascular medicine. Wide-genome association studies are currently being carried out and a number of candidate genes are being identified. However, results have to be taken with caution before they are reproduced in different populations. Further studies will involve detailed comparisons of gene and protein expression in specific plaque regions from coronary and carotid arteries at different stages of development. By identifying genes and pathways involved in progression towards instability, these techniques will help to transform treatment [134].

\section{Conclusions}

Large population-based studies, like the Framingham Study, clearly demonstrated the co-existence between coronary and carotid artery disease. The severity of atherosclerosis in one vascular bed was related to the severity in the other peripheral arteries. Both entities shared similar risk factors. Further, the IMT of the common carotid and the internal carotid arteries or the presence of atherosclerotic plaque was strongly associated with the risk of MI and stroke. This suggests that coronary and carotid atherosclerosis evolve simultaneously. In respect to symptomatic coronary or carotid artery disease some clear variances exist. Disruption of small lesions and local formation of large occluding thrombus are important in the pathogenesis of acute MI. In contrast, in the carotid territory low to moderate stenosis remains usually clinically asymptomatic and large plaques generally have only small intramural thrombi. However, microemboli may form at the surface of the ulcerated carotid plaque and lead to cerebral strokes or asymptomatic silent infarcts. On anatomopathology, large coronary plaques tend to be fibrotic and stable, while carotids with severe stenosis usually are unstable with ulceration, intraplaque hemorrhage, important inflammation and big lipidic core. Carotid artery plaques appear at a much higher age, suggesting that defence mechanisms protecting carotids are much better developed than in the case of coronary arteries. Individual responses to shear stress may partially explain differences between coronary and carotid atherothrombosis. Variability in the plaque composition between coronary and carotid arteries exists and marks differences in the pathophysiology of both diseases. Plaque heterogenous cellular population contributes independently to single vascular events and changes throughout the life of the coronary and carotid artery. These cellular and molecular hallmarks are the main cause of the difference between two territories, atherosclerotic plaque progression and resistance to common risk factors. The remodelling properties of both territories are possibly driven by different plaque composition at different stages of disease evolution. The adequate understanding of dynamic pathophysiology of both diseases may offer numerous approaches to treat patients in the future. This concept will be supported by current studies, especially those of wide-genome association analysis of coronary and carotid disease patients. It is expected that new target genes and molecules will be identified in the near future.

\section{References}

1 Vink A, Schoneveld A, Richard W, Keijn D, Falk E, Borst C, Pasterkamp G: Plaque burden, arterial remodelling, and plaque vulnerability: determined by systemic factors? J Am Coll Cardiol 2001;31:718-723.

-2 Hankey GJ, Warlow CP: Cost-effective investigation of patients with suspected transient ischaemic attacks. J Neurol Neurosurg Psychiatry 1992;55:171-176.

- 3 Sacco Rl, Shi T, Zamanillo MC, Kargman DE: Predictors of mortality and recurrence after hospitalized cerebral infarction in an urban community: the Northern Manhattan Stroke Study. Neurology 1994;44:626-634.
4 Viitanen M, Eriksson S, Asplund K: Risk of recurrent stroke, myocardial infarction and epilepsy during long-term follow-up after stroke. Eur Neurol 1988;28:227-231.

5 Iwamoto T: Clinical significance of carotid artery lesions. Nippon Ronen Igakkai Zasshi 2002;39:516-519.

- 6 Rubio F, Martinez-Yelamos S, Cardona P, Krupinski J: Carotid endarterectomy: is it still a gold standard? Cerebrovasc Dis 2005; 20(suppl 2):119-122.

\footnotetext{
Cotter G, Cannon CP, McCabe CH, Michowitz Y, Kaluski E, Charlesworth A, Milo O, Bentley J, Blatt A, Krakover R, Zimlichman R, Reisin L, Marmor A, Lewis B, Vered Z, Caspi A, Braunwald E: Prior peripheral arterial disease and cerebrovascular disease are independent predictors of adverse outcome in patients with acute coronary syndromes: are we doing enough? Results from the Orbofiban in patients with Unstable Coronary Syndromes-Thrombolysis in Myocardial Infarction (OPUS-TIMI) 16 study. Am Heart J 2003;145:622-627.
} 
-8 Wilson PW: Established risk factors and coronary artery disease: the Framingham study. Am J Hypertens 1994;7:7S-12S.

-9 Kaplan RC, Tirschwell DL, Longstreth WT, Manolio TA, Heckbert SR, LeValley AJ, Lefkowitz D, El-Saed A, Psaty BM: Blood pressure level and outcomes in adults aged 65 and older with prior ischaemic stroke. J Am Geriatr Soc 2006;54:1309-1316.

10 Brown DW, Giles WH, Greenlund KJ: Blood pressure parameters and risk of fatal stroke, NHANES II mortality study. Am J Hypertens 2007;20:338-341.

11 Breuer MW: Characteristics of atherosclerotic plaque in diabetics. Herz 2002;27:189192.

12 Roberts CK, Chen AK, Barnard RJ: Effect of a short-term diet and exercise intervention in youth on atherosclerotic risk factors. Atherosclerosis 2007;191:98-106.

13 Stensland-Bugge E, Bonaa KH, Joakinson O: Age and sex differences in the relationship between inherited and lifestyle risk factors and sub-clinical carotid atherosclerosis: the Tromso study. Atherosclerosis 2001;154: 437-448.

14 Luedemann J, Schminke U, Berger K, Piek M, Willich S, Doring A, John U, Kessler C: Association between behavior-dependent cardiovascular risk factors and asymptomatic carotid atherosclerosis in a general pop ulation. Stroke 2002;33:2929-2935.

15 Wang H, Fan D, Zhang, H, Fu Y, Zhang J, Shen Y: Serum level of homocysteine is correlated with carotid artery atherosclerosis in Chinese with ischaemic stroke. Neurol Res 2006;28:25-30.

16 Husmann M, Barton M: Therapeutic potential of direct thrombin inhibitors for atherosclerotic vascular disease. Expert Opin Investig Drugs 2007;16:563-567.

17 Lozzi A, Miconi R, Panzini E, Monaldo M, Raffa S: D-dimer assays in patients with carotid atherosclerosis in clinical practice. Minerva Cardioangiol 2000;48:97-102.

-18 Liapis CD, Paraskevas KI: Factors affecting recurrent carotid stenosis. Vasc Endovasc Surg 2005;39:83-95.

19 Chol BG, Viles-Gonzalez JF, Badimon JJ: The role of high density lipoprotein cholesterol in atherothrombosis. Mt Sinai J Med 2006;73:690-701.

20 Rader DJ: Mechanism of disease: HDL metabolism as a target for novel therapies. Nat Clin Pract Cardiovasc Med 2007;4:102-109.

-21 Lund Haheim L, Holme I, Hjermann I, Tonstad S: Risk factor profile for the incidence of subarachnoid and intracerebral haemorrhage, cerebral infarction, and unspecified stroke during 21 years' follow-up in men. Scand J Public Health 2006;34:589-597.

22 Wahle KW: Atherosclerosis: cell biology and lipoproteins. Curr Opin Lipidol 2001;12 363-365.
23 Vasankari T, Toikka J, Mikkola J, Irjila K, Pasanen P, Neuvorenen K, Viikari J: Oxidized LDL and thickness of carotid intimamedia are associated with coronary atherosclerosis in middle-aged men: lower levels of oxidized LDL with statin therapy. Atherosclerosis 2001;155:403-412.

-24 Nilsson J, Nordin Fredrikson G, Schiopu A, Shah PK, Jansson B, Carlsson R: Oxidised LDL antibodies in treatment and risk assessment of atherosclereosis and associated cardiovascular disease. Curr Pharm Des 2007; 13:1021-1030.

25 Tanaka A, Ai M, Kobayashi Y, Tamura M, Shimokado K, Numano F: Metabolism of triglyceride-rich lipoproteins and their role in atherosclerosis. Ann NY Acad Sci 2001;947: 207-212.

26 Sacks F, Alaupovic P, Moye LA, Cole TG, Sussex B, Stampfer MJ, Pfeffer MA, Braunwald E: VLDL, apolipoproteins B, CIII, and $\mathrm{E}$, and risk of recurrent coronary events in the Cholesterol and Recurrent Events (CARE) trial. Circulation 2000;102:18861892

-27 Ward S, Lloyd Jones M, Pandor A, Holmes M, Ara S, Ryan A, Yeo W, Payne N: A systematic review and economic evaluation of statins for the prevention of coronary events. Health Technol Assess 2007;11:1-160, iii-iv.

28 De Michele M, Panico S, Lannuzzi A, Celentano E, Ciardullo A, Galasso R, Sacchetti L, Zarrilli F, Bond G, Rubba P: Association of obesity and central fat distribution with carotid artery wall thickening in middle-aged women. Stroke 2002;33:2923-2928.

-29 Mannami T, Konishi M, Baba S, Nishi N, Terao A: Prevalence of asymptomatic carotid atherosclerotic lesions detected by high-resolution ultrasonography and its relation to cardiovascular risk factors in the general population of a Japanese city: the Suita study. Stroke 1997;28:518-525.

- 30 O'Leary D, Polak J, Kronmal R, Manolio T, Burke G, Wolfson S: Carotid-artery intima and media thickness as a risk factor for myocardial infarction and stroke in older adults: Cardiovascular Health Study Collaborative Research Group. N Engl J Med 1999;340:1422.

-31 Held C, Hiemdahl P, Eriksson SV, Bjorkander I, Forslund L, Rehnqvist N: Prognostic implications of intima-media thickness and plaques in the carotid and femoral arteries in patients with stable angina pectoris. Eur Heart J 2001;22:62-72.

32 O'Leary D, Polak J, Kronmal R, Savage P, Borhani N, Tracy R, Gardin J, Price T, Furberg C: Thickening of the carotid wall: a marker for atherosclerosis in the elderly? Cardiovascular Health Study Collaborative Research Group. Stroke 1996;27:224-231.

33 Mack WJ, LaBree L, Liu C, Selzer RH, Hodis $\mathrm{HN}$ : Correlations between measures of atherosclerosis change using carotid ultrasonography and coronary angiography. Atherosclerosis 2000;150:371-379.
34 Sen S, Wu K, McNamara R, Lima J, Piantadosi S, Oppenheimer SM: Distribution, severity and risk factors for aortic atherosclerosis in cerebral ischemia. Cerebrovasc Dis 2000;10:102-109.

35 Hodis HN: Reversibility of atherosclerosisevolving perspectives from two arterial imaging clinical trials: the cholesterol lowering atherosclerosis regression study and the monitored atherosclerosis regression study. J Cardiovasc Pharmacol 1995;25:S25-S31.

36 Toubal P-J, Elbaz A, Koller G, Lucas C, Adrai V, Chedru F, Amarenco P: Common carotid artery intima-media thickness and brain infarction: the GENIC case control study. Circulation 2000;102:313-318.

- 37 Kanters SD, Algra A, van Leeuwen MS, Banga JD: Reproducibility of in vivo carotid intima-media thickness measurements: a review. Stroke 1997;28:665-671.

- 38 Juonala M, Viikari JS, Rasdanen L, Helenius $\mathrm{H}$, Pletikainen M, Raltakari QT: Young adults with family history of coronary heart disease have increased arterial vulnerability to metabolic risk factors: the Cardiovascular Risk in Young Finns Study. Arterioscler Thromb Vasc Biol 2006;26:1376-1382.

39 Schminke U, Luedemann J, Berger K, Alte D, Mitusch R, Wood WG, Jaschinski A, Barrow S, John U, Kessler C: Association between alcohol consumption and sub-clinical atherosclerosis: the study of health in Pomerania. Stroke 2005;36:1746-1752.

40 Adams G, Simoni D, Bordelon C, Wesley G, Kimball K, Insull W, Morrisett J: Bilateral symmetry of human carotid artery atherosclerosis. Stroke 2002;33:2575-2580.

41 Font MA, Fernandez A, Turu MM, Gamez C, Slevin M, Rubio F, Badimon L, Krupinski J: Metabolic proinflammatory activity in human carotid artery plaques is detected by (18)FDG-PET imaging prior to endarterectomy. Stroke 2007;38:587.

42 Valgimigli M, Agostini P, Serruys PW: Acute coronary syndromes: an emphasis shift from treatment to prevention. J Cardiovasc Med 2007;8:221-229.

-43 de Feyter PJ, van den Brand M, Laarman GJ, van Domburg R, Serruys PW, Surypranata $\mathrm{H}$ : Acute coronary artery occlusion during and after percutaneous transluminal coronary angioplasty. Frequency, prediction, clinical course, management, and follow-up. Circulation 1991;83:927-936.

-44 Kragel AH, Gertz SD, Roberts WC: Morphologic comparison of frequency and types of acute lesions in the major epicardial coronary arteries in unstable angina pectoris, sudden coronary death and acute myocardial infarction. J Am Coll Cardiol 1991;18: 801-818. 
45 Fernandez-Ortiz A, Badimon JJ, Falk E, Fuster V, Meyer B, Mailhac A, Weng D, Shah PK, Badimon LK: Characterization of the relative thrombogenicity of atherosclerotic plaque components: implications for consequences of plaque rupture. J Am Coll Cardiol 1994;23:1562-1569.

-46 Harker LA, Hanson SR, Wilcox JN, Kelly AB: Antithrombotic and antilesion benefits without hemorrhagic risks by inhibiting tissue factor pathway. Haemostasis 1996;26 (suppl 1):76-82.

-47 Toschi V, Gallo R, Lettino M, Fallon JT, Gertz SD, Fernández-Ortiz A, Chesebro JH, Badimon L, Nemerson Y, Fuster V, Badimon JJ: Tissue factor modulates the thrombogenicity of human atherosclerotic plaques. Circulation 1997;95:594-599.

-48 Virmani R, Burke AP, Kolodgie FD, Farb A: Pathology of the thin-cap fibroatheroma: atype of vulnerable plaque. J Interv Cardiol 2003;16:267-272.

-49 Kolodgie FD, Gold HK, Burke AP, Fowler DR, Kruth HS, Weber DK, Farb A, Guerrero LJ, Hayase M, Kutys R, Narula J, Finn AV, Virmani R: Intraplaque hemorrhage and progression of coronary atheroma. N Engl J Med 2003;349:2316-2325.

50 Virmani R, Kolodgie FD, Burke AP, Finn AV, Gold HK, Tulenko TN, Wrenn SP, Narula J: Atherosclerotic plaque progression and vulnerability to rupture: angiogenesis as a source of intraplaque hemorrhage. Arterioscler Thromb Vasc Biol 2005;25:2054-2061.

-51 Cola C, Clementi E, Biondi-Zoccai G, Sangiorgi G: From carotid plaque biology to serologic markers of vulnerability to predict the risk of cerebrovascular events. Acta Chir Belg 2007;107:129-142.

52 Libby P: Molecular basis of the acute coronary syndromes. Circulation 1995;91:28442850.

53 Loftus IM, Thompson MM: The role of matrix metalloproteinases in vascular disease. Vasc Med 2002;7:117-133.

54 Newby AC: Dual role of matrix metalloproteinases (matrixins) in intimal thickening and atherosclerotic plaque rupture. Physiol Rev 2005;85:1-31.

-55 Newby AC: Do metalloproteinases destabilize vulnerable atherosclerotic plaques? Curr Opin Lipidol 2006;17:556-561.

- 56 Meredith IT, Anderson TJ, Uehata A, Yeung AC, Selwyn AP, Ganz P: Role of endothelium in ischemic coronary syndromes. Am J Cardiol 1993;72:27C-31C.

-57 Willeit J, Kiechl S, Oberhollenzer F, Rungger G, Egger G, Bonora E, Mitterer M, Muggeo M: Distinct risk profiles of early and advanced atherosclerosis: prospective results from the Bruneck study. Arterioscler Thromb Vasc Biol 2000;20:529-537.
58 Krupinski J, Turu MM, Font MA, Ahmed N, Sullivan M, Luque A, Rubio F, Badimon L, Slevin M: Increased tissue factor, MMP-8, and $\mathrm{D}$-dimer expression in diabetic patients with unstable advanced carotid atherosclerosis. Vasc Health Risk Manag 2007;3:1-8.

-59 Spence JD, Eliasziw M, DiCicco M, Hackam DG, Galil R, Lohmann T: Carotid plaque area: a tool for targeting and evaluating vascular preventative therapy. Stroke 2002;33: 2916-2922.

60 Sitzer M, Siebler M, Rose G, Steinmetz H: Cerebral microembolism in atherosclerotic carotid artery disease: facts and perspectives. Funct Neurol 1995;10:251-258.

61 Rothwell PM, Gibson R, Warlow CP: Interrelation between plaque surface morphology and degree of stenosis on carotid angiograms and the risk of ischemic stroke in patients with symptomatic carotid stenosis. On behalf of the European Carotid Surgery Trialists' Collaborative Group. Stroke 2000;31: 615-621.

62 Segura T, Serena J, Castellanos M, Teruel J, Vilar C, Davalos A: Embolism in acute middle cerebral artery stenosis. Neurology 2001; 56:497-501.

63 Pedro L, Pedro M, Goncalves I, Carneiro T, Balshina C, Fernandes R, Fernandes J: Computer-assisted carotid plaque analysis: characteristics of plaques associated cerebrovascular symptoms and cerebral infarction. Eur J Vasc Endovasc Surg 2000;19:118-123.

64 Mosorin M, Surcel H, Laurila A, Karttunen R, Juvonen J, Paavonen J, Morrison R, Juvonen T: Detection of Chlamydia pneumoniae-reactive $\mathrm{T}$ lymphocytes in human atherosclerotic plaques of carotid artery. Arterioscler Thromb Vasc Biol 2000;20:10611067.

65 Irvine CD, George SJ, Sheffield E, Johnson JL, Davies AH, Lamont PM: The association of platelet-derived growth factor receptor expression, plaque morphology and histological features with symptoms in carotid atherosclerosis. Cardiovasc Surg 2000;8: 121-129.

66 Ballotta E, Da Giau G, Renon L: Carotid plaque gross morphology and clinical presentation. A prospective study of 457 carotid artery specimens. J Surg Res 2000;89:7884.

67 Bassiouny HS, Davis H, Massawa N, Gewertz BL, Glagov S, Zarins CK: Critical carotid stenoses: morphologic and chemical similarity between symptomatic and asymptomatic plaques. J Vasc Surg 1989;9:202-212.

68 Gronholdt ML, Wiebe BM, Laursen $\mathrm{H}$ Nielsen TG, Schroeder TV, Sillesen H: Lipidrich carotid artery plaques appear echolucent on ultrasound B-mode images and may be associated with intraplaque haemorrhage. Eur J Vasc Endovasc Surg 1997; 14:439-445.

-69 Feeley TM, Leen EJ, Colgan MP, Moore DJ, Hourihane DO, Shanik GD: Histologic characteristics of carotid artery plaque. J Vasc Surg 1991;13:719-724.
70 Gronholdt ML: Ultrasound and lipoproteins as predictors of lipid-rich, rupture-prone plaques in the carotid artery. Arterioscler Thromb Vasc Biol 1999;19:2-13.

71 Leen EJ, Feeley TM, Colgan MP, O’Malley MK, Moore DJ, Hourihane DO, Shanik GD: 'Hemorrhagic' carotid plaque does not contain hemorrhage. Eur J Vasc Surg 1990;4: 123-128.

72 Golledge J, Cuming R, Ellis M, Davies AH, Greenhalgh RM: Carotid plaque characteristics and presenting symptom. Br J Surg 1997;84:1697-1701.

73 Liapis CD, Kakisis JD, Kostakis AG: Recurrent carotid artery stenosis: natural history and predisposing factors. A long-term follow-up study. Int Angiol 2001;20:330-336.

74 Krupinski J, Catena E, Miguel M, Domenech P, Vila R, Morchon S, Rubio F, Cairols M, Slevin M, Badimon L: D-dimer local expression is increased in symptomatic patients undergoing carotid endarterectomy. Int J Cardiol 2007;116:174-179.

75 Turu MM, Krupinski J, Catena E, Rosell A, Montaner J, Rubio F, Alvarez-Sabin J, Cairols M, Badimon L: Intraplaque MMP-8 levels are increased in asymptomatic patients with carotid plaque progression on ultrasound. Atherosclerosis 2006;187:161-169.

76 Lal BK, Hobson RW, Hameed M, Pappas PJ, Padberg FT, Jamil Z, Duran WN: Noninvasive identification of the unstable carotid plaque. Ann Vasc Surg 2006;20:167-174.

77 Li Z, Howarth S, Tang T, Graves M, U-KingIm J, Kirkpatrick P, Gillard J: Structural analysis and magnetic resonance imaging predict plaque vulnerability: a study comparing symptomatic and asymptomatic individuals. J Vasc Surg 2007;45:768-775.

78 Momiyama Y, Kato R, Fayad ZA, Tanaka N, Taniguchi H, Ohmori R, Kihara T, Kameyama A, Miyazaki K, Kimura K, Arakawa K, Kusuhara M, Nagata M, Nakamura H, Ohsuzu F: A possible association between coronary plaque instability and complex plaques in abdominal aorta. Arterioscler Thromb Vasc Biol 2006;26:903-909.

79 Gonzalez Ramirez J, Armesto V, Manuel Crespo J: Carotid intraplaque hemorrhage: MRI findings. Radiologia 2006;48:107-110.

$>80$ de Neelfer R, Verkelf CJ, van der Tureen JM, Jukema JW, van der Waal JW, van Berkel T, Baker JW, Blessen EA: Lesional overexpression of matrix metalloproteinase-9 promotes intraplaque hemorrhage in advanced lesions but not at earlier stages of atherogenesis. Arterioscler Thromb Vasc Biol 2006;26:340346.

-81 Pierce MC, Park BH, de Boer JF, Whittaker P, Bouma BE, Bressner E, Halpern E, Houser SL, Tearney GJ: Measurement of collagen and smooth muscle cell content in atherosclerotic plaques using polarization-sensitive optical coherence tomography. J Am Coll Cardiol 2007;49:1474-1481. 
82 Clarkson TB, Anthony MS, Klein KP: Effects of estrogen treatment on arterial wall structure and function. Drugs 1994;47(suppl 2): 42-51.

83 Davies MJ, Thomas AC: Plaque fissuring the cause of acute myocardial infarction, sudden ischaemic death, and crescendo angina. Br Heart J 1985;53:363-373.

84 Sinapius D: Morphology of occlusive coronary thrombi. Localization, length, composition, growth. Dtsch Med Wochenschr 1972;97:544-546.

-85 Toschi V, Gallo R, Lettino M, Fallon JT, Gertz SD, Fernandez-Ortiz A, Chesebro JH, Badimon L, Nemerson Y, Fuster V, Badimon JJ: Tissue factor modulates the thrombogenicity of human atherosclerotic plaques. Circulation 1997;95:594-599.

86 Meyer BJ: Unstable angina pectoris: coagulation disorder and its therapy. Schweiz Rundsch Med Prax1995;84:232-238.

-87 Jander S, Sitzer M, Wendt A, Schroeter M, Buchkremer M, Siebler M, Müller W, Sandmann W, Stoll G: Expression of tissue factor in high-grade carotid artery stenosis. Stroke 2001;32:850-854.

88 Krupinski J, Turu MM, Font MA, Catena E, Slevin M, Morchon S, Rubio F, Badimon L, Martínez-González J: Blood-borne tissue factor activity predicts major cerebrovascular events in patients undergoing carotid endarterectomy: results from 1-year followup study. Cerebrovasc Dis 2007;25:32-39.

89 Virmani R, Burke AP, Farb A, Kolodgie FD: Pathology of the unstable plaque. Prog Cardiovasc Dis 2002;44:349-356.

90 Nicholls S, Tuzcu EM, Wolski K, Sipahi I, Schoenhagen P, Crowe T, Kapadia SR, Hazen SL, Nissen SE: Coronary artery calcification and changes in atheroma burden in response to established therapies. J Am Coll Cardiol 2007;49:263-270.

-91 Schmermund A, Erbel R: Unstable coronary plaque and its relation to coronary calcium. Circulation 2001;104:1682-1687.

92 Nossen JM, Vierzigmann T, Lang E: Calcified plaques of extracranial carotid arteries and left ventricular geometry as predictors of coronary artery disease. Med Klin (Munich) 2003;98:72-78.

93 Saito D, Shiraki T, Oka T, Kajiyama A, Doi M, Masaka T: Morphological correlation of atherosclerotic lesions of the carotid and coronary arteries in patients with angina pectoris. Jpn Circ J 1999;63:522-526.

\$4 Katritsis DG, Pantos J, Efstathopoulos E: Hemodynamic factors and atheromatic plaque rupture in the coronary arteries: from vulnerable plaque to vulnerable coronary segment. Coron Artery Dis 2007;18:229-237.

95 Spence J, Norris J: Infection, inflammation, and atherosclerosis. Stroke 2003;34:333334 .
96 Hansson GK: Inflammation, atherosclerosis, and coronary artery disease. N Engl Med 2005;352:1685-1695.

-97 Asai Y, Takaori K, Yamamoto T, Ogawa T: Protein-bound polysaccharide isolated from basidiomycetes inhibits endotoxininduced activation by blocking lipopolysaccharide-binding protein and CD14 function. FEMS Immunol Med Microbiol 2005;43:91-98.

$\$ 98$ Soilleux EJ, Morris LS, Trowsdale J, Coleman N, Boyle JJ: Human atherosclerotic plaques express DC-SIGN, a novel protein found on dendritic cells and macrophages. J Pathol 2002;198:511-516.

-99 Beaudeux JL, Giral P, Bruckert E, Bernard M, Foglietti MJ, Chapman MJ: Serum matrix metalloproteinase- 3 and tissue inhibitor of metalloproteinases-1 as potential markers of carotid atherosclerosis in infraclinical hyperlipidemia. Atherosclerosis 2003;169:139-146.

100 Fong I: Emerging relations between infectious diseases and coronary artery disease and atherosclerosis. CMAJ 2000;163:4956.

101 Vallance P, Collier J, Bhagat K: Infection, inflammation, and infarction: does acute endothelial dysfunction provide a link? Lancet 1997;349:1391-1392.

102 Gurfinkel E, Bozovich G: Chlamydia pneumoniae: inflammation and instability of the atherosclerotic plaque. Atherosclerosis 1998;140:S31-S35.

103 Chiu B: Multiple infections in carotid atherosclerosis plaques. Am Heart J 1999;138: S534-S536.

104 Muhlestein J, Anderson J, Hammond E, Zhao L, Trehan S, Schwobe EP, Carlquist JF: Infection with Chlamydia pneumoniae accelerates the development of atherosclerosis and treatment with azathromycin prevents it in a rabbit model. Circulation 1998; 97:633-636.

105 Grau AJ, Buggle F, Becher H, Werle E, Hacke W: The association of leukocyte count, fibrinogen and C-reactive protein with vascular risk factors and ischemic vascular diseases. Thromb Res 1996;82:245255

106 Rost NS, Wolf PA, Kase CS, Kelly-Hayes M, Silbershatz H, Massaro JM, D’Agostino RB, Franzblau C, Wilson PW: Plasma concentration of C-reactive protein and risk of ischemic stroke and transient ischemic attack: the Framingham study. Stroke 2001; 32:2575-2581.

107 Ridker PM: Should statin therapy be considered for patients with elevated C-reactive protein? The need for a definitive clinical trial. Eur Heart J 2001;22:2135-2137.

108 Ridker PM, Buring JE, Cook NR, Rifai N: C-reactive protein, the metabolic syndrome, and risk of incident cardiovascular events: an 8-year follow-up of 14,719 initially healthy American women. Circulation 2003;107:391-397.
109 Krupinski J, Turu MM, Slevin M, Martinez-Gonzalez J: Carotid plaque, stroke pathogenesis, and CRP: treatment of ischemic stroke. Curr Treat Options Cardiovasc Med 2007;9:229-235.

110 Di Napoli M, Papa F, Bocola V: C-reactive protein in ischemic stroke: an independent prognostic factor. Stroke 2001;32:917-924.

111 Lusis A: Atherosclerosis. Nature 2000;407: 233-241.

112 Krupinski J, Turu MM, Martinez-Gonzalez J, Carvajal A, Juan-Babot JO, Iborra E, Slevin M, Rubio F, Badimon L: Endogenous expression of C-reactive protein is increased in active (ulcerated noncomplicated) human carotid artery plaques. Stroke 2006;37:1200-1204

113 Blann AD, McCollum CN: von Willebrand factor and soluble thrombomodulin as predictors of adverse events among subjects with peripheral or coronary atherosclerosis. Blood Coagul Fibrinolysis 1999;10:375380.

114 Fox C, Polak J, Chazaro I, Cupples A, Wolf P, D’Agostino R, O’Donnell C: Genetic and environmental contributions to atherosclerosis phenotypes in men and women. Stroke 2003;34:397-402.

115 Duggirala R, Gonzalez V, O’Leary D, Stern $\mathrm{M}$, Blangero J: Genetic bases of variation in carotid artery wall thickness. Stroke 1996; 27:833-837.

116 Nanda NC, Kitzman DW, Dittrich HC, Hall G: Imagent improves endocardial border delineation, inter-reader agreement, and the accuracy of segmental wall motion assessment. Echocardiography 2003;20: 151-161.

117 Schmidt H, Schmidt R, Niederkorn K, Gradert A, Schumacher M, Watzinger N, Hartung H, Kostner G: Paraoxonase PON1 polymorphism leu-Met54 is associated with carotid atherosclerosis: results of the Austrian Stroke Prevention Study. Stroke 1998;29:2043-2048.

118 WilleitJ,KiechlS, Oberhollenzer F, Rungger G, Egger G, Bonora E, Mitterer M, Muggeo M: Distinct risk profiles of early and advanced atherosclerosis: prospective results from the Bruneck Study. Arterioscler Thromb Vasc Biol 2000;20:529-537.

119 Pfohl M, Fetter M, Koch M, Barth C, Rudiger W, Haring $\mathrm{H}$ : Association between angiotensin I-converting enzyme genotypes, extracranial artery stenosis, and stroke. Atherosclerosis 1998;140:161-166.

120 White AJ, Duffy SJ, Walton AS, Ng JF, Rice GE, Mukherjee S, Shaw JA, Jennings GL, Dart AM, Kingwell BA: Matrix metalloproteinase-3 and coronary remodeling: implications for unstable coronary disease. Cardiovasc Res 2007;75:813-820. 
121 Rosenblat M: Human serum paraoxonases (PON1) Q and R selectively decrease lipid peroxides in human coronary and carotid atherosclerotic lesions: PON1 esterase and peroxidase-like activities. Circulation 2000;101:2510-2517.

122 Hunt KJ, Duggirala R, Goring HH, Williams JT, Almasy L, Blangero J, O’Leary DH, Stern MP: Genetic basis of variation in carotid artery plaque in the San Antonio Family Heart Study. Stroke 2002;33:27752780.

123 Zhang QJ, Goddard M, Shanahan C, Shapiro L, Bennett M: Differential gene expression in vascular smooth muscle cells in primary atherosclerosis and in stent stenosis in humans. Arterioscler Thromb Vasc Biol 2002;22:2030-2036.

124 Goldbourt U, Neufeld HN: Genetic aspects of atherosclerosis. Arteriosclerosis 1988;6: 357-377.

125 Bell J: Predicting disease using genomics. Nature 2004;429:453-456.

126 Roses AD: Pharmacogenetics and the practice of medicine. Nature 2000;405:857865.
127 Crook SA, Rosenzweig A: DNA microarrays, implications for cardiovascular medicine. Circ Res 2002;91:559-564.

128 Satterthwaite G, Francis SE, Suvarna K, Blakemore S, Ward C, Wallace D, Braddock M, Crossman D: Differential gene expression in coronary arteries from patients presenting with ischemic heart disease: further evidence for the inflammatory basis of atherosclerosis. Am Heart J 2005; 150:488489.

129 Archacki SR, Angheloiu G, Tian XL, Tan FL, DiPaola N, Shen GQ, Moravec C, Ellis S, Topol EJ, Wang Q: Identification of new genes differentially expressed in coronary artery disease by expression profiling. Physiol Genomics 2003;15:65-74.

130 Ijas P, Nuotio K, Saksi J, Soinne L, Saimanen E, Karjalainen-Lindsberg ML, Salonen O, Tuimala J, Kovanen PT, Kaste M, Lindsberg PJ: Microarray analysis reveals overexpression of CD163 and HO-1 in symptomatic carotid plaques. Arterioscler Thromb Vasc Biol 2007; 1:154-160
131 Martinet W, Schrijvers DM, De Meyer GR, Thielemans J, Knaapen MW, Herman AG, Kockx MM: Gene expression profiling of apoptosis-related genes in human atherosclerosis: upregulation of death-associated protein kinase. Arterioscler Thromb Vasc Biol 2002;22:2023-2029.

132 Slevin M, Elasbali AB, Miguel Turu M, Krupinski J, Badimon L, Gaffney J: Identification of differential protein expression associated with development of unstable human carotid plaques. Am J Pathol 2006; 168:1004-1021.

133 Vaisar T, Pennathur S, Green PS, Gharib SA, Hoofnagle AN, Cheung MC, Byun J, Vuletic S, Kassim S, Singh P, Chea H, Knopp RH, Brunzell J, Geary R, Chait A, Zhao XQ, Elkon K, Marcovina S, Ridker P, Oram JF, Heinecke JW: Shotgun proteomics implicates protease inhibition and complement activation in the antiinflammatory properties of HDL. J Clin Invest 2007;117:746756.

134 Miller DT, Ridker PM, Libby P, Kwiatkowski DJ: Atherosclerosis: the path from genomics to therapeutics. J Am Coll Cardiol 2007;49:1589-1599. 